\title{
Spatial analysis of intra-site use at a Late Paleolithic site at Shuidonggou, Northwest China
}

\author{
GUAN Ying $^{1,2}$, GAO Xing ${ }^{1 *}$, WANG HuiMin ${ }^{3}$, CHEN FuYou ${ }^{1}$, PEI ShuWen ${ }^{1}$, \\ ZHANG XiaoLing ${ }^{1} \&$ ZHOU Zhen $\mathrm{Yu}^{1,2}$

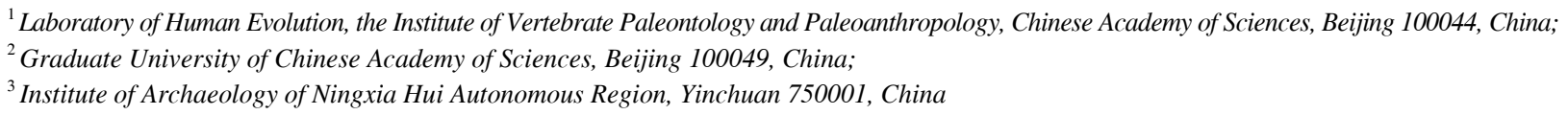

Received March 23, 2011; accepted June 30, 2011; published online August 30, 2011

\begin{abstract}
Intra-site spatial analysis provides an alternative perspective for understanding the functions of a site, and the occupational organization of early human living and activities associated with it. We examined features and cultural remains recovered from Locality 2 at Shuidonggou, a Late Paleolithic site, focusing on early occupants' survival behaviors and settlement patterns, as indicated by evidence regarding the functional organization of the site. Three-dimensional data from unearthed remains (including lithic assemblages, faunal remains, ornaments, etc) were used to reconstruct intra-site use patterns of Cultural Layer 2, which yielded seven earth-pit hearths and tens of thousands of artifacts and bones. We discuss the population size and group composition, as well as the functions of the living spaces, based on the analysis of the hearth patterns and the ostrich eggshell ornaments surround the hearths. In conclusion, Cultural Layer 2 of SDG Locality 2 appears to have functioned as a base camp for ancient foragers, where occupants produced tools, as well as preparing and consuming food.
\end{abstract}

Shuidonggou, Late Paleolithic, intra-site study, spatial analysis

Citation: Guan Y, Gao X, Wang H M, et al. Spatial analysis of intra-site use at a Late Paleolithic site at Shuidonggou, Northwest China. Chinese Sci Bull, 2011, 56: 3457-3463, doi: 10.1007/s11434-011-4682-x

The organization and use of living space by ancient humans constitute important parameters for evaluating the evolution of social structure and relationships between family and group members [1-5]. As early as the Late Paleolithic period, social structure was reflected in the distribution and use of living space, organization of survival behavior, relationships and interactions between group members, and even ancient religious activities. Features of social structure can be reconstructed by examining cultural remains recovered from archaeological sites and their spatial distribution in paleosurfaces, or "living floors", at examined sites. The current study examined cultural remains from Cultural Layer 2 of the Shuidonggou Locality 2 site (referred to as "SDG Loc. 2 " hereafter). We interpret the results in terms of ancient human behavior and the functions of the site, and

\footnotetext{
*Corresponding author (email: gaoxing@ivpp.ac.cn)
}

discuss survival strategies and social organization of foragers in the SDG area.

\section{Intra-site use pattern and spatial analysis}

Generalized site structure refers to the spatial distribution and relationships of features, artifacts, and other evidence within a given archaeological site [6,7]. This distribution and corresponding relationships are a result of the activities of ancient occupants (i.e. the material residues of human behaviors), rather than natural forces [8]. Therefore, the ultimate goal of studying site structure is to interpret patterns of ancient human behaviors, or intra-site use.

In evaluating intra-site use patterns, four major factors should be considered: (1) the conditions of preservation; (2) assemblages of stone artifacts and bone artifacts [9]; (3) the 
distribution and relation of all the unearthed remains [10,11]; and (4) the area range and location of the site [7]. Traditional analysis of the living floor focused on two-dimensional factors, evaluating social and individual activities through the relationships of cultural remains on the same living floor [12-14]. Recently, an increasing number of researchers have applied three-dimensional coordinates, placing the archaeological remains not only in the horizontal plane, but also vertical and three-dimensional space, redefining "living floor" and "discrete activity area", and discussing discrete occupational events in the same anthropogenic layer or paleosurface [15]. At the same time, post-depositional disturbance is also considered, so the site formation process and real-life time events can be accurately reconstructed [16]. The analyses and interpretations of these factors provide the main content of spatial analysis, which can shed new light on reconstruction of site functions and ancient human behaviors at prehistoric camps.

\section{Archaeological context}

The SDG site is an open-air site located $18 \mathrm{~km}$ east of Yinchuan City, the capital of the Ningxia Hui Autonomous Region (subsequently referred to as Ningxia), Northwest China (Figure 1). In 1923, French geologists Pierre Teilhard de Chardin and Emile Licent discovered a rich assemblage of stone artifacts and vertebrate fossils in Pleistocene fluvial sands and gravels in the SDG area and named the site after the locality $[17,18]$. The site complex yielded cultural remains between 30-11 ka BP [19-21]. Among the localities, SDG Loc.2 was excavated recently, exposing an area of $80 \mathrm{~m}^{2}$, which yielded five anthropogenic layers, or cultural layers, in the deposit. Tens of thousands of cultural remains were unearthed, including stone artifacts, animal bones, ostrich eggshell ornaments, and other materials, and earthpit hearths have also been documented. Stone artifact assemblages at this site are predominantly small debris and chunks, followed by flakes, cores, and tools (Table 1). The ratio of tools to total materials recovered is relatively low, and the tools are predominantly scrapers and points. The assemblages resemble the Small Flake Tool Cultural Complex, representing the typical characteristics of Late Paleolithic assemblages in North China. Dating results from this site are discussed in detail in several previous articles [19-21], so will not be elaborated here. Stratigraphically, excavation level 6 , which is considered the second cultural layer (CL2) of SDG Loc.2, consists of light yellow silt with a maximum thickness of $30 \mathrm{~cm}$, yielding stone artifacts, animal bones and ash. Ten dating estimates have been obtained for CL2, the oldest of which is $29520 \pm 230$ a BP. The youngest estimate is $23790 \pm 180$ a BP, while the others fall between 28000 and 25000 a BP.

We selected CL2 for spatial analysis for the following reasons: (1) the excavation area of CL2 is relatively large; (2) the dating results have been verified with stratigraphic

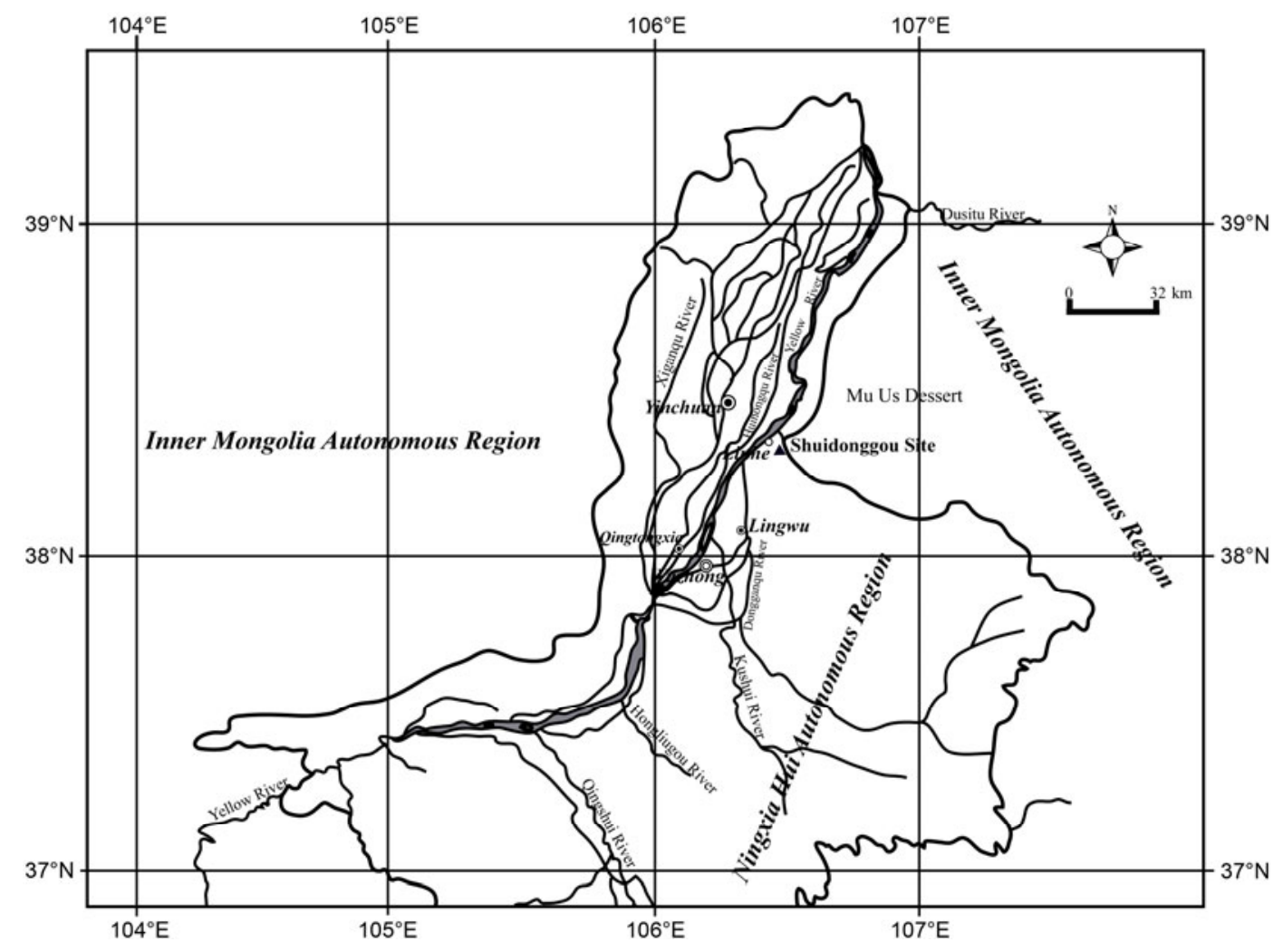

Figure 1 The location of SDG Loc.2. 
Table 1 Unearthed specimens from cultural layers 1-3

\begin{tabular}{|c|c|c|c|c|c|c|c|c|c|c|c|c|c|c|c|c|c|}
\hline \multirow{2}{*}{ Layer } & \multicolumn{2}{|c|}{ Flake } & \multicolumn{2}{|c|}{ Core } & \multicolumn{2}{|c|}{ Tool } & \multicolumn{2}{|c|}{ Chunk } & \multicolumn{2}{|c|}{ Fragment } & \multicolumn{2}{|c|}{ Bone } & \multicolumn{2}{|c|}{ Ornament } & \multicolumn{2}{|c|}{ Bipolar product } & \multirow{2}{*}{$\begin{array}{c}\text { Total } \\
\mathrm{N}\end{array}$} \\
\hline & $\mathrm{N}$ & $\%$ & $\mathrm{~N}$ & $\%$ & $\mathrm{~N}$ & $\%$ & $\mathrm{~N}$ & $\%$ & $\mathrm{~N}$ & $\%$ & $\mathrm{~N}$ & $\%$ & $\mathrm{~N}$ & $\%$ & $\mathrm{~N}$ & $\%$ & \\
\hline CL1 & 700 & 5.86 & 77 & 0.65 & 169 & 1.42 & 3294 & 27.60 & 6727 & 56.36 & 215 & 1.80 & 0 & 0 & 754 & 6.32 & 11936 \\
\hline CL2 & 334 & 9.64 & 11 & 0.32 & 71 & 2.05 & 224 & 6.47 & 1842 & 53.19 & 877 & 25.32 & 74 & 2.14 & 30 & 0.87 & 3463 \\
\hline CL3 & 76 & 6.29 & 19 & 1.57 & 9 & 0.75 & 136 & 11.26 & 841 & 69.62 & 115 & 9.52 & 0 & 0 & 11 & 0.91 & 1207 \\
\hline Total & 1110 & 6.68 & 107 & 0.64 & 249 & 1.50 & 3654 & 22.00 & 9410 & 56.66 & 1207 & 7.27 & 74 & 0 & 795 & 4.79 & 16606 \\
\hline
\end{tabular}

data and shown to be reliable; (3) a large quantity of cultural materials have been recovered; (4) silt deposits were only minimally affected by fluvial action; and (5) the three-dimensional data of unearthed specimens were recorded with a NikonDTM352C Total Station, which could be accurately reconstructed by computerization. These data provide a basic foundation for spatial analysis of CL2 in SDG Loc.2.

\section{Intra-site studies}

\subsection{Evaluating the integrity of the living floor}

The first step of spatial analysis is to evaluate whether the distribution of cultural remains in the living floor was due to ancient occupants' activities, or to other natural factors causing post-depositional disturbances. We examined specimens from CL1-3, and the proportions of different types of specimen are presented in Table 1. Total stone debris (long axes $<20 \mathrm{~mm}$ ) constituted $56.66 \%$ of all specimens, with a three-layer average reach of $59.72 \%$. In addition, a large number of stone debris which long axes shorter than $10 \mathrm{~mm}$ were sieved without individual record numbers and were not counted, meaning that the actual proportion of stone debris is likely to be much higher. According to Shick [22], deposits are barely affected by natural forces if small unearthed stone artifacts (long axes $<20 \mathrm{~mm}$ ) constitute $60 \%-$ $70 \%$ of specimens, while cores represent less than $10 \%$. Therefore, the distribution of cultural remains in the living floor are likely due to the actual ancient occupants' activities.

On the other hand, stone artifacts from CL1-3 exhibit an extremely low degree of weathering and abrasion, which is indicative of instant accumulation by silt without suffering transportation of water, or other natural agencies.

The orientations of the long axes of SDG Loc. 2 artifacts, when unearthed, were also recorded, and are evenly distributed into different directions. When unearthed, stone artifacts were laid in no particular orientation, but tended to be between $0^{\circ}-10^{\circ}$ in level angle, indicating that the specimens were relatively level with the surface.

The evidence discussed above indicates that the content of CL2 is likely to reflect genuine remnants of human activity, minimally affected by post-depositional distortion. In addition, there was no evidence of a geological fault, fold or other geological disturbance in the excavation area, so the distribution and relationship of specimens in CL2 should represent genuine temporal events.

The vertical distribution of unearthed specimens in SDG Loc. 2 is shown in Figure 2. In the section, the area of artifact density shows where the earth-pit hearths were recovered, reflected in the high concentrations of human activities around the hearths. Although there was an unexcavated area between $\mathrm{T} 1$ and $\mathrm{T} 2$, a connection between areas $\mathrm{T} 1$ and $\mathrm{T} 2$ can be inferred based on the consistent profiles of the two excavation pits. CL2 could not be divided into sublayers indicating that CL2 was deposited during a continuous period.

"Occupational event [7,23-25]" is defined here as a single occurrence of uninterrupted human use of a space. Even an anthropogenic layer cannot be divided into sublayers, the palimpsest phenomenon would still provide misleading data regarding the establishment of genuine periods of occupation $[2,12,26,27]$. Accurate evaluation of occupational

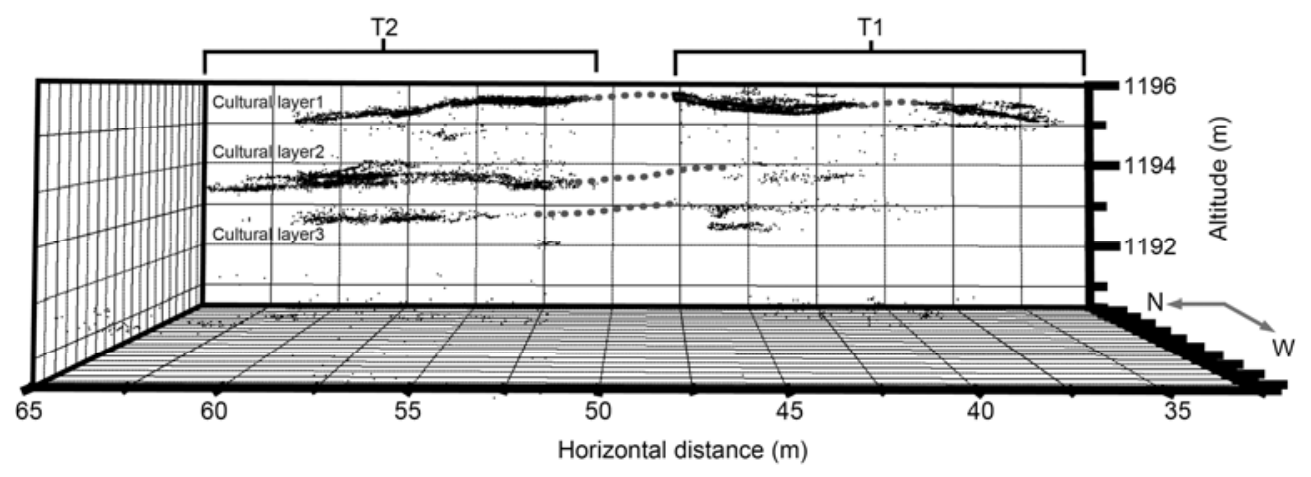

Figure 2 The vertical distribution of unearthed specimens in SDG Loc.2 (the dotted lines refer to unexcavated areas). 
events could be helpful in understanding the frequency of space usage, and the characteristics and patterns of camp space organization. The main indicator of occupational events is the existence of hearths. The number, size and distribution pattern of hearths can reflect the extent of camp space usage, and consequently reflect the residence status of ancient occupants.

\subsection{Spatial distribution of recovered specimens}

As the main indicator of occupational events, hearths were recovered in CL2. At least seven hearths were recorded on the living floor (numbered $\mathrm{H} 1-7$ in Figure 3), with area ranges of 2, 4, 2, 2, 2, 1 and $1 \mathrm{~m}^{2}$, respectively. Flakes, cores, tools, chunks, debris, bones, ostrich eggshell beads and fragments were scattered around the hearths. H1-4 exhibited the highest density, followed by H5-6, while H7 contained a small number of stone debris and bones. Stone tool types exhibited more variation around H1-4 than H5-6 (Figure 3).

Ostrich eggshell beads and fragments recovered surround H1-6 are main features of CL2. At present, there is no ethnographic record that can confirm a direct relationship between hearths and bead fabrication. Thus, we speculate that the distribution we observed is due to a hearth-centered activity pattern, related to the use of fire for warmth and light. In addition, a bone needle was recovered near $\mathrm{H} 1$, indicating cloth-making or other handcraft activity.

Although CL2 was deposited during a continuous period, separate occupational events would be expected for the seven hearths, with each occurring at a different time. Ethnographic data and other aspects of the archaeological record indicate that hearths present in the same living floor are typically spaced $1.7-4 \mathrm{~m}$ apart $[6,7,28,29]$. In the present study, some hearths were approximately $1 \mathrm{~m}$ apart, but most hearths were not next to each other (Figure 4). However, in
CL2, apart from $\mathrm{H} 7$, the other hearths were all relatively close, and even overlapped in some cases. This finding indicates that the hearths may have resulted from overlapping occupations, possibly representing a case of the palimpsest phenomenon, which means different living floors were pressed together, and could not be separated stratigraphically. Binford conducted a study of hearth-centered behavior, reporting that a circle defined by the area occupied by seated persons surrounding the hearth regularly measured $1.76 \mathrm{~m}$ in radius from the center of a hearth [30]. This circular area is thus likely to determine the distance separating the nearest hearths. Based on this conclusion, Henry introduced $1.8 \mathrm{~m}$ as a parameter for distinguishing different occupational episodes at the Tar Faraj Cave site [26]. In accord with these previous studies, we applied a parameter of $1.8 \mathrm{~m}$ in our hearth pattern analysis of SDG Loc.2.

The horizontal distribution and $1.8 \mathrm{~m}$ parameter indicate that $\mathrm{H} 2$ was not from the same occupational event as H1, 3, or 4. Likewise, H4 and 5 appeared to originate from different events, as did H5 and 6. In other words, the data indicated that H1, 3, 4, 6, and 7 may have existed at the same time, while $\mathrm{H} 2$ and 5 existed at different times. Thus, five appears to be the maximum number of contemporaneous hearths at the site, while the minimum number of hearths at any time was one. Any hearth could be present by itself. In summary, the results indicate that the seven hearths in CL2 were due to at least two occupational events, and at most seven events.

Based on the occupational events results, hearths can be separated into two groups: H1, 3, 4, 6, 7 in Group 1, and H2 and 5 in Group 2. Consequently, there are three possibilities regarding the existence of hearths: (1) only Group 1 is present; (2) only Group 2 is present; and (3) the two groups were cross-existent. According to Formula (1)-(3), there are 45 possible scenarios of hearth patterns.
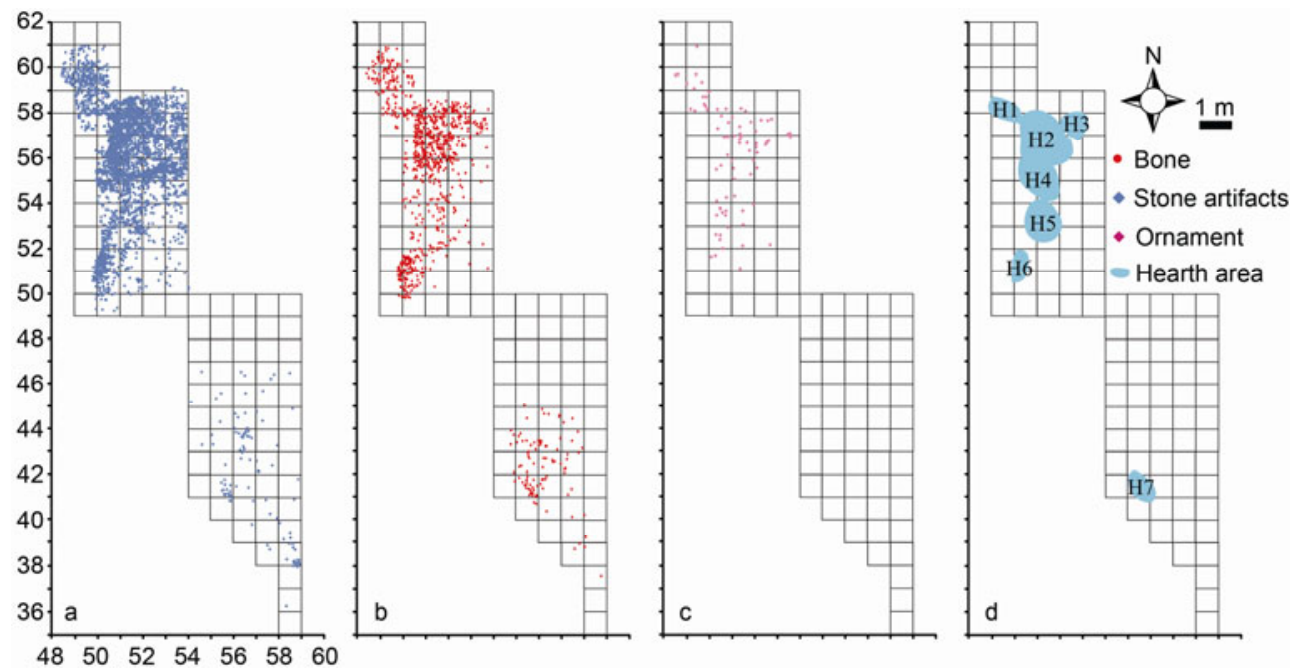

Figure 3 The distribution of different specimens in cultural layer 2 of SDG Loc.2. a, Stone artifacts; b, animal bones; c, ornaments and ostrich eggshell fragments; $d$, hearth area. 


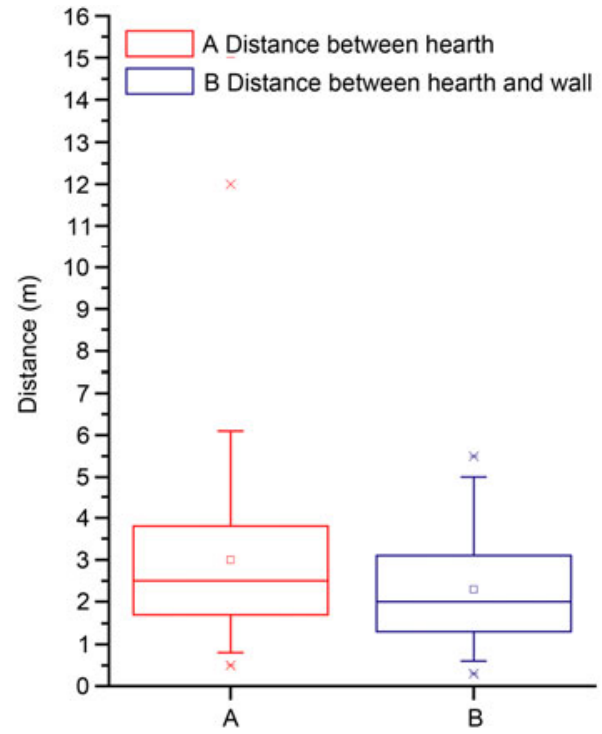

Figure 4 The distance statistic of hearths based on ethnographic data (Henry, 2003 [6]).

Group 1: H1, H3, H4, H6, H7

$$
\begin{aligned}
& \left\{\begin{array}{l}
1 \text { Hearth : } C_{5}^{1}=\frac{5 !}{1 !(5-1) !}=5 \\
2 \text { Hearths: } C_{5}^{2}=\frac{5 !}{2 !(5-2) !}=10 \\
3 \text { Hearths: } C_{5}^{3}=\frac{5 !}{3 !(5-3) !}=10 \\
4 \text { Hearths: } C_{5}^{4}=\frac{5 !}{4 !(5-4) !}=5 \\
5 \text { Hearths: } C_{5}^{5}=\frac{5 !}{5 !(5-5) !}=1
\end{array}\right\}=31 \\
& \text { Group 2: H2, H5 }\left\{\begin{array}{l}
1 \text { Hearth: } \mathrm{C}_{2}^{1}=\frac{2 !}{1 !(2-1) !}=2 \\
2 \text { Hearth: } \mathrm{C}_{2}^{2}=\frac{2 !}{2 !(2-2) !}=1
\end{array}\right\}=3
\end{aligned}
$$

Group $1+$ Group 2

$$
\left\{\begin{array}{c}
\mathrm{H} 2+\text { Group 1: } \mathrm{C}_{2}^{2}+\mathrm{C}_{2}^{1}=\frac{2 !}{2 !(2-2) !}+\frac{2 !}{1 !(2-1) !}=3 \\
\mathrm{H} 5+\text { Group 1: } \mathrm{C}_{3}^{3}+\mathrm{C}_{3}^{2}+\mathrm{C}_{3}^{3}=\frac{3}{3 !(3-3) !}+\frac{3 !}{2 !(3-2) !} \\
+\frac{3 !}{1 !(3-1) !}=7 \\
\mathrm{H} 2+\mathrm{H} 5+\text { Group 1: } \mathrm{C}_{1}^{1}=\frac{1 !}{1 !(1-1) !}=1
\end{array}\right\}=11
$$

As mentioned above, the oldest dating result is $29520 \pm$
230 a $\mathrm{BP}$, the youngest is $23790 \pm 180$ a $\mathrm{BP}$, and the others fall between 28000-25000 a BP. If the oldest and the youngest results are excluded, the time range is approximately $3 \mathrm{ka}$, indicating that the oldest occupation event would not be 3 ka older than the youngest.

The hearth pattern analysis indicated at least two occupational events in CL2, with a maximum interval of $3 \mathrm{ka}$. At each event, there is evidence that the occupants conducted a range of activities, including flaking, tool fabrication, ornament making, food preparation and food consumption, suggesting that CL2 constituted a base camp where the ancient occupants lived around central hearths.

\section{Discussion}

\subsection{The spatial organization of SDG Loc.2}

The cultural remains and features recovered in CL2 indicate a hearth-centered behavior pattern at the site. The results suggest that the occupants of the site conducted a range of activities around the hearths, including stone artifact manufacture, ornament fabrication, sewing handcraft, food processing and food consumption, so that the hearth- circle area exhibited the highest specimen density. This density gradually decreased with greater distances from the hearth. This pattern of behavior appears to have caused the lens-shaped profile-view density and three-dimensional distribution of specimens in the deposits. In addition, this implies that no walls were constructed on the living floor, which would have blocked the scattering of stone debris or bone fragments. However, it remains unclear whether occupants built small shelters for sleeping or other activities. Future studies are required to provide more archaeological evidence to elucidate this question.

\subsection{Group size, social composition and human behavior}

Conducting activities around hearths requires a certain amount of physical space. Freeman proposed that one individual can conveniently reach an area of $2.5-3 \mathrm{~m}^{2}$ [31]. Viewed as a circular area, this would constitute a diameter of approximately 1.80-1.94 m [26]. Combined with Binford's $1.76 \mathrm{~m}$ assumption, one hearth could thus provide activity space for 1-5 persons. With more than five persons the space would be crowded and unsuitable for regular behavior.

In summary, the seven hearths in CL2 appear to be associated with between two and seven discrete occupational events, with a minimum and maximum of one and five hearths, respectively. When only one hearth existed, the group would be expected to contain between one and five people. With five hearths, a group of between five and 25 people would be expected.

Bone needle and ostrich eggshell ornaments indicate that SDG Loc. 2 occupants had already acquired sophisticated and specialized handcraft techniques. In terms of ornament 
construction, which constitutes a time-consuming activity requiring specialized techniques, we propose three alternative hypotheses of labor division: (1) random assignment, in which group members select any duty without special assignment; (2) females-seniors assignment, in which females and elders perform relatively low-level physically strain tasks in a group, since they might not be capable of hunting or other more physically-demanding duties. Handcraft working would thus be assigned to people who are more mindful. This pattern reflects low-level labor division, such that task assignment is based on the physical characteristics of group members; and (3) specific working team assignment, involving special working teams such as a "hunting team", a "gathering team" and a "handcrafting team". The main decisive factor in this case is an individual's skill-level. Under this system, all working teams would act together to perform different tasks in parallel, constituting a systematic and characteristically human social division of labor. As a major characteristic of Upper Paleolithic communities, division of labor was common during the later stages of the Pleistocene. Thus, the "female-elders assignment" and "specific working team assignment" hypotheses are more likely to have been implemented at SDG Loc. 2 than a "random assignment" regime. Thus, certain occupants might have functioned as artisans of ostrich eggshell ornament production.

The stone artifact assemblages at SDG Loc. 2 resemble the typical Small Flake Tool Cultural Complex in North China. This cultural complex existed from a very early time to the last stage of the Chinese Paleolithic. As such, we propose that stone artifact makers were aboriginal foragers who evolved from archaic populations in East Asia.

The construction of bone needle represents the exploration of bone materials, while ostrich eggshell ornament manufacture reflect body decoration and aesthetic pursuit. These features are conventionally thought to be absent during the Early Paleolithic period, and are considered to indicate the self-awareness and identity of individuals as well as social groups [4]. These phenomena and the recovered hearths at our study site thus indicate modern human behaviors.

\subsection{Site functions}

The CL2 of SDG Loc.2 appears to constitute a residential camp of ancient humans. Our findings indicate that the occupants of this residential camp undertook a range of activities, including tool fabrication and maintenance, food preparation and consuming, clothing production, and ornament manufacture, centered around a number of hearths. The wide variation in stone artifacts at the site indicates a long duration of occupation, with the presence of a large number of debris, chunks, cores and flakes, as well as some raw materials [11]. In addition, other features and remnants have been recovered, indicating multiple intra-site activities. The living floor CL2 in SDG Loc.2 thus represents complex and diverse cultural content (Table 1, Figure 5).

\section{Conclusion}

CL2 of SDG Loc. 2 appears constitute a base camp of ancient foragers. Paleoenvironmental data $[19,32,33]$ indicate that the ancient SDG area was predominantly an open grassforest environment containing some small lakes and rivers. The occupants lived beside the lakeshore or riverbank, at convenient locations for obtaining water. Food resources including animal and plant material were abundant at this site, which could support the survival of the occupant. The intra-site use pattern of CL2 indicated a hearth-central living pattern. The presence of bone needle and ostrich eggshell ornaments imply a division of labor, providing the

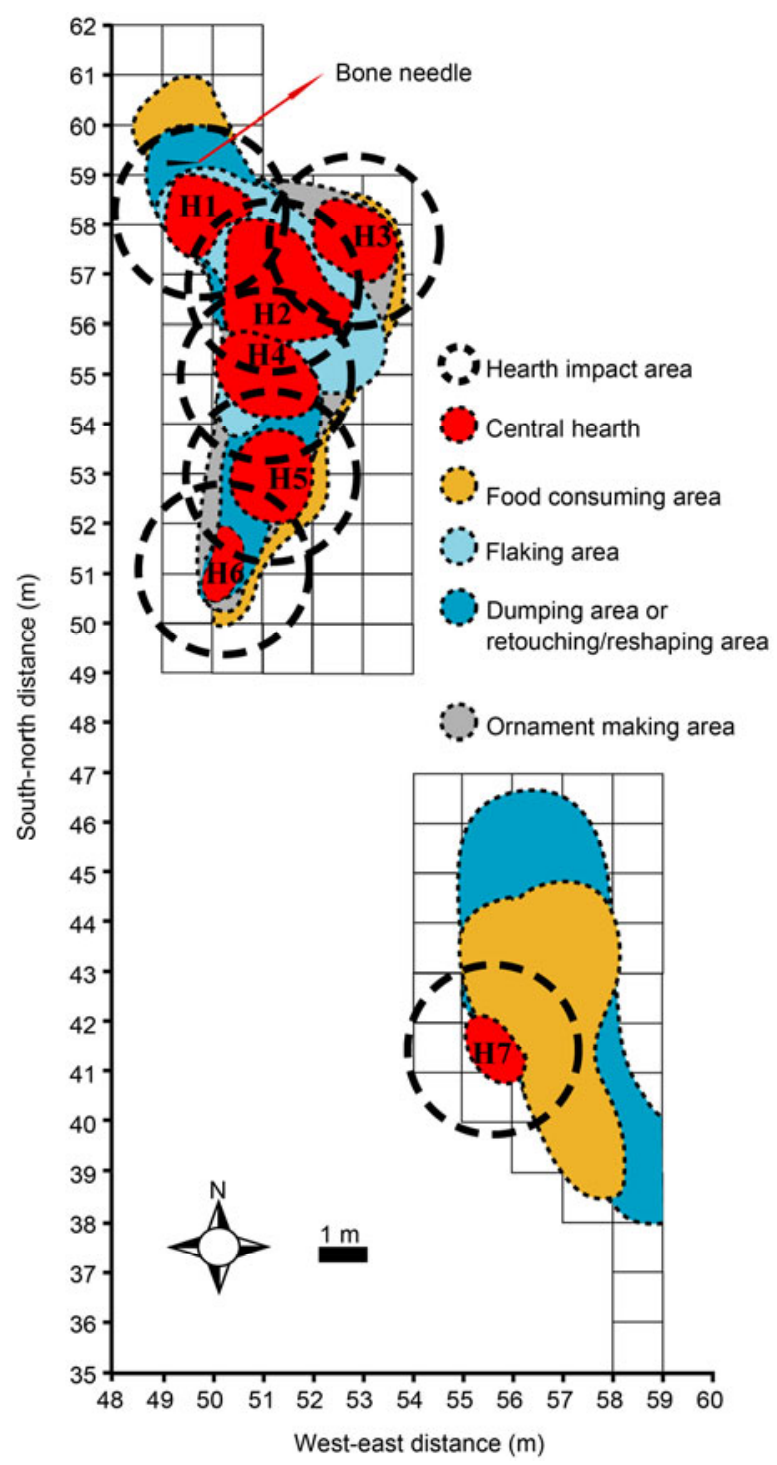

Figure 5 The functional areas of cultural layer 2 in SDG Loc.2. 
earliest evidence of labor division in Late Paleolithic China.

The features of the living floor in CL2 have significant implications for other cultural layers. Regarding stone artifact assemblages and the distribution of artifacts and features, all cultural layers share strong similarities. Therefore, CL1, 3, 4, and 5 also appear likely to represent base camps. However, the excavation area restricts our understanding of the site characteristics, and might limit integral estimation. One way of resolving this problem is to complement the data with analyses of stone artifact typology and refitting. Alternatively, expanding the excavation area to acquire more evidence at the site may also help to address this issue. Comprehensive intra-site studies in future could provide further important breakthroughs.

We thank Zhong Kan, Feng Xingwu, Luo Zhigang, Mei Huijie, Liu Decheng, Zhang Yue, Wang Chunxue, Peng Fei, Ma Ning, Li Feng, Yi Mingjie et al. for their contributions with the fieldwork. Shen Chen helped rewrite the manuscript in English. This work was supported by the Knowledge Innovation Program of the Chinese Academy of Sciences (KZCX2-YW-Q1-04), the Strategic Priority Research Program of the Chinese Academy of Sciences (XDA05130202) and the National Basic Research Program of China (2010CB950203).

1 Bar-Yosef O. The archaeological framework of the Upper Paleolithic revolution. Diogenes, 2007, 54: 3-18

2 Straus L G. Of stones and bones: Interpreting site function in the Upper Paleolithic and Mesolithic of Western Europe. J Anthropol Archaeol, 2006, 25: 500-509

3 Bicho N, Haws J, Hockett B. Two sides of the same coin-rocks, bones and site function of Picareiro Cave, central Portugal. J Anthropol Archaeol, 2006, 25: 485-499

4 Bar-Yosef O. The Upper Paleolithic revolution. A Rev Anthropol, 2002, 31: 363-393

5 Deacon H J. Southern Africa and modern human origins. Philos Trans R Soc Lond B, 1992, 337: 177-183

6 Henry D O. Behavioral organization at Tor Faraji. In: Henry D O, ed. Neanderthals in the Levant: Behavioral Organization and the Beginnings of Humen Modernity. London, New York: Continuum, 2003. 237-270

7 Binford L R. In Pursuit of the Past: Decoding the Archaeological Record. New York: Thames and Hudson Inc., 1983

8 Schiffer M B. Formation Processes of the Archaeological Record. Albuquerque: University of New Mexico Press, 1987

9 Andrefsky Jr W. Lithic-Macroscopic Approaches to Analysis. Cambridge: Cambridge University Press, 1998

10 Henry D. Intrasite spatial patterns and behavioral modernity indications from the Late Levantine Mousterian rockshelter of Tor Faraj, Southern Jordan. In: Akazawa T, Aoki K, Bar-Yosef O, eds. Neanderthals and Modern Humans in Western Asia. New York: Plenum Press, 2002. 127-142

11 Kooyman B P. Understanding Stone Tools and Archaeological Sites. Albert and Aluquerque: University of Calgary Press and University of New Mexico Press, 2000
12 Carr C. Dissecting intra-site artefact palimpsests using Fourier methods. In: Kent S, ed. Method and Theory for Activity Area Research: An Ethnoarchaeological Approach. New York: Columbia University Press, 1987. 236-291

13 Hietala H J. Intrasite Spatial Analysis in Archaeology. Cambridge: Cambridge University Press, 1984

14 Simek J F. Integrating pattern and context in spatial archaeology. J Archaeol Sci, 1984, 11: 405-420

15 Anderson K L, Burke, A. Refining the definition of cultural levels at Karabi Tamchin: A quantitative approach to vertical intra-site spatial analysis. J Archaeol Sci, 2008, 35: 2274-2285

16 Roe D. Introduction: Precise moments in remote time. World Archaeol, 1980, 12: 107-108

17 Licent E, Teilhard de chardin P. Le Paleolithique, de la Chine. L'Anthropologie, 1925, 25: 201-234

18 Boule M, Breuil H, Licent E, et al. Le Pateolithique de la Chine. Paris: Archives de l'institut de Paleontologie Humaine, 1928

19 Gao X, Yuan B, Pei S, et al. Analysis of sedimentary-geomorphologic variation and the living environment of hominids at the Shuidonggou Paleolithic site. Chinese Sci Bull, 2008, 53: 2025-2032

20 Liu D, Wang X, Gao X, et al. Progress in the stratigraphy and geochronology of the Shuidonggou site, Ningxia, North China. Chinese Sci Bull, 2009, 54: 3880-3886

21 Gao X, Li J, Madsen D B, et al. New ${ }^{14} \mathrm{C}$ dates for Shuidonggou and related discussions (in Chinese). Acta Anthropol Sin, 2002, 21: 211-218

22 Shick K D. Stone age sites in making, experiments in the formation and transformation of archaeological occurrences. British Archaeological Report, Oxford, 1986

23 Die P S. Spatial analisys of Bolomor Cave level IV (Tavernes de la Valldigna, Valencia). Ann dell'Univ Stud Ferrara Museol Sci Nat, 2008, Special Volume: 155-160

24 Rossignol J, Wandsnider L. Space, Time and Archaeological Landscapes. New York: Plenum Press, 1992

25 Vaquero M, Pastó I. The Definition of spatial units in Middle Palaeolithic sites: The hearth-related assemblages. J Archaeol Sci, 2001, 28: 1209-1220

26 Henry D. The palimpsest problem, hearth pattern analysis, and Middle Paleolithic site structure. Quat Int, (in press)

27 Farizy C. Spatial patterning of Middle Paleolithic sites. J Anthropol Archaeo, 1994, 13: 153-160

28 Henry D O. Human behavioral organization in the Middle Paleolithic: Were Neanderthals different? Am Anthropolog, 2004, 106: 17-31

29 Gamble C. The Paleolithic Settlement of Europe. Cambridge: Cambridge University Press, 1986

30 Binford L R. Hearth and home, the spatial analysis of ethnographically documented rock shelter occupations as a template for distinguishing between human and hominid use of sheltered space. In: Conard N, Wendorf F, eds. Middle Paleolithic and Middle Stone Age Settlement Systems. Forlí: A.B.A.C.O, Edizioni, 1996. 229-239

31 Freeman L. Mousterian worked bone from Cueva Morin (Santander, Spain), a preliminary description. In: Freeman L G, ed. Views of the Past, Essays in Old World Prehistory and Paleoanthropology. Chicago: Aldine, 1978. 29-52

32 Liu D. A comparison study of human survival environment in Zhijidong and Shuidonggou Areas During MIS3 (in Chinese). Dissertation for the Doctoral Degree. Beijing: Department of Geography, Peking University. 2008

33 Zhou K, Hu J. Environment and stratigraphy at the Shuidonggou site (in Chinese). Acta Anthropol Sin, 1988, 7: 263-269

Open Access This article is distributed under the terms of the Creative Commons Attribution License which permits any use, distribution, and reproduction in any medium, provided the original author(s) and source are credited. 